\title{
Our sister journal, Nature Clinical Practice Cardiovascular Medicine, to publish original research
}

\author{
Hannah Camm and Suzanne J Farley
}

The Editor-in-Chief, Dr Valentin Fuster, is pleased to announce that original clinical research papers can now be submitted to Nature Clinical Practice Cardiovascular Medicine.

Currently with the same remit and layout as Nature Clinical Practice Nephrology, Nature Clinical Practice Cardiovascular Medicine has provided a comprehensive monthly overview of advances in cardiology and associated fields for the past 3 years. The editorial staff feel that the addition of outstanding original clinical research to the latest review content will provide everything that busy cardiologists and affiliated healthcare professionals need in order to keep up to date with advances in their areas of expertise.

The synergies between the practices of nephrology and cardiology are obvious. As such, readers of Nature Clinical Practice Nephrology might well be working on an original research project that would be suitable for submission to Nature Clinical Practice Cardiovascular Medicine. Why should you or your cardiology colleagues submit your best clinical research to our sister publication? Our parent journal, Nature, is synonymous with editorial excellence and integrity and, as such, we have a huge amount of experience and expertise to draw on. Furthermore, Nature Clinical Practice Cardiovascular Medicine is a global publication; its links with the World Heart Foundation are evidence of the journal's commitment to the global community. The editorial staff believe that original research from every country should be rapidly disseminated
... readers ... might well be working on an original research project that would be suitable for submission to Nature Clinical

Practice

Cardiovascular Medicine

HCamm is

Editor of Nature

Clinical Practice

Cardiovascular

Medicine and

SJ Farley is Editor of Nature Clinical Practice Nephrology.

Competing interests The authors declared no competing interests.

www.nature.com/clinicalpractice doi:10.1038/ncpneph0639 and reach the world stage. Submissions from all over the world are, therefore, encouraged.

Original research published in Nature Clinical Practice Cardiovascular Medicine will fall primarily, albeit not exclusively, into three main categories: the development of new technology or methodology that improves understanding of cardiovascular disease or has an impact on diagnosis or management; new information on clinical outcomes and economics from clinical trials; and new approaches to the promotion of cardiovascular health. What will make the journal's original clinical research papers different from those published elsewhere is that each will be accompanied by a commentary that will put the new findings into clinical context, much like our unique Practice Point articles. In line with the ethos of Nature Clinical Practice-translating the latest research findings into clinical practice-the latest clinical research will be showcased, and a forum provided for leaders in the field to interpret, in the context of recent literature, the impact that novel data will have on clinical practice.

At Nature Publishing Group we pride ourselves on our innovative attitude to publishing and our high editorial standards. Our international advisory boards of leaders in their fields, our editorial integrity and our rigorous peer review system make us confident that Nature Clinical Practice Cardiovascular Medicine will provide you with clinical research of the highest standard. For more information, please visit the journal's website at www.nature.com/ncpcardio. 